to the number of notified cases of tuberculosis in his area. It was, consequently, considered necessary to take steps to ensure that due attention should be paid to the question of the proper and due attention should be paid to the question of the proper and
periodical revision of the tuberculosis register. The Public Health periodical revision of the tuberculosis register. The Public Health
(Tuberculosis) Regulations, 1924, dated 18th December, 1924 (Statutory Rules and Orders, 1924, No. 1411), have therefore been issued."

The steady diminution since 1917 in the mortality from non-pulmonary tuberculosis is a redeeming feature, and is attributed partly to a safer milk supply, partly to institutional isolation of advanced cases of pulmonary tuberculosis, and partly to extended facilities for residential treatment of non-pulmonary cases, with excellent results even in severe bone and joint conditions. Indeed, the care of the advanced case, whether pulmonary or not, is an important influence in limiting spread of infection in families, and it is very desirable that small units of hospital accommodation should be available within easy reach of the homes of patients, though such units should bo so administered as not to acquire the reputation of being merely homes for the dying.

Regarding the subject of results of sanatorium treatment, reference is made to the report issued by the Medical Research Council in July, 1924, as to patients treated at Frimley Sanatorium. Notwithstanding disappointed hopes, it is held that sanatorium treatment "offers a more solid prospect of general all-round gain to the community in the conbat against this disease," and that "at present, there is no alternative." The points to be attended to are early notification, sufficient period of residence, sound principles properly applied, and after-care assistance. Care and after-care, occupational training, and methods of treatment, including vaccine therapy, are all discussed in this valuable section of the report, but space forbids their further exposition here.

\section{ATMOSPHERIC POLLUTION.}

The pollution of the ocean of the atmosphere in which we are all immersed nay be regarded as one of those evils called necessary which are inseparable from civilization in temperate latitudes. Dust is universal in the city and even in the country. Smoke is being continually discharged into the atmosphere; and every day the everincreasing volume of heavy traffic is grinding down woorl, stone, and metal into impalpable particles to be blown about by every breeze. All this is quite apart from the myriads of minute living things-yeasts, other fungi, bacteria, spores, etc.-which contribute their substance to the omnipresent dust.

In 1912 a Smoke Abatement Exhibition was held in London, and one of the things accomplisher by the delegates of the municipal authorities present was the establishment of a committee for the investigation of atmospheric pollution. This committee has now issued its tenth report.* It covers the work of the year ending March, 1924, the twelfth year of activity. 'The committee consists of members appointed by the Meteorological Office, by the Department of Scientific and Industrial Research, and by a technical subcommittee of experts, representing chemistry, physics, engineering, and other applied sciences. Sir Napier Shaw, F.R.S., is chairman.

The method of measuring the aerial pollution by means of the "standard gauge" has been fully described in previous reports. In the year under review forty-five gauges were in operation. Besides reporting upon the total deposit of impurities, the committee was able to estimate all of the following materials which contribute to the pollution of the atmosphere-namely, soluble ash, ash soluble on ignition, tar, carbonaceous matter, sulphates, chlorine, and ammonia. Saturdays and Sundays, for obvious reasons, are studied in a group by themselves, the other days being called "week-days."

All days for the purposes of this study are divided into two types: ordinary days and " $z$ " days, the latter being those on which the smoke haze was at some hour very thick.

* The Tenth Annual Report of the Committee for the Investigation of Atmospheric Pollution. Meteorological Office: Air Ministry H.M. Atmospheric Pollution. (Pp. 53; 16 figures. 4s, Air.)
A " $z$ " day is defined as one during any portion of which the maximum impurity is equal to or greater than 1.28 milligrams of dirt per cubic metre of air. Three types of instrument have been used: (1) the standard deposit gauge, the purpose of which is to collect the deposited impurity at any station so as to compare the amounts which fall in different localities; (2) the automatic filter, which hourly measures the amount of suspended impurity; and (3) the jet dust counter, which allows of a microscopical examination and enumeration of the dust particles. A new form of instrument is described, the settlement dust counter, designed by Dr. J. S. Owens, the consulting engineer. It measures the amount of dust or bacteria in the air even when the dust particles are very coarse, such as are found in warehouses for grain and in similar buildings. The ordinary method of exposing a plate has little value as a quantitative method, for the deposit on such a plate varies as the size of the particles, their density, the temperature of the air, and the degree of its turbulence. Further, the deposit is made from an unknown volume of air.

The figures for the total deposits are striking. Expressed in metric tons to a hundred square kilometres of surface a year (omitting hundreds) we have: for London from 8,000 to 16,000 ; for Glasgow from 9,000 to 12,000 ; for Central Birmingham 17,000; for Blackburn 8,000; for Leeds from 15,000 to 16,0C0; for Newcastle-upon-Tyne 34,000; for St. Helens 16,000; for Liverpool from 23,000 to 25,000 . At Blackburn in winter there were $47 \mathrm{per}$ cent. ordinary days and 53 per cent. " $\mathrm{z}$ " days. In summer in Blackburn on a week-day the deposit of impurity begins about 4 a.m., rising to a maximum at 7 a.m.; whereas on Sundays the maximum is not reached until $10 \mathrm{a} . \mathrm{m}$.; this is taken to mean that the inhabitants, by remaining longer in bed on Sundays, prolong by three hours the period of matutinal salubrity.

The ratio of total smoke on Sundays to week-days in that town is as 2,000 to 3,077 . Assuming that the Sunday smoke is exclusively domestic, while the week-day is domestic plus factory, the ratio of factory to domestic smoke is as 1 to 1.85. The instruments of precision have permitted a high degree of accuracy being attained in this work.

In previous years it had been found that 10,000 particles went to a milligram: the observations now reported confirm this; about 10,000 particles per cubic centimetre correspond to 0.8 milligrams per cubic metre.

Research is being conducted into the ability of light to penetrate haze or fog-a subject of great practical consequence. As might have been expected, the greater the number of particles suspended, the greater is the percentage of light thereby obstructed. The contrast photometer is used to measure the amount of light transmitted through a known distance of hazy atmosphere. In round numbers, there is a loss of 50 per cent. of light in traversing 50 feet of air when there are present 32,000 particles per c.cm.-that is, by 2.6 milligrams per cubic metr. As we ascend from the ground, the number and size of the particles diminish, as has been ascertained through observations by aviators.

The average diameter of particles collected at the surface was about four times that of those at 10,000 feet; so that the ratio of the total weight of particles at the surface of the ground to that of those at 10,000 feet was 530 to 1 .

The spectroscopic appearance of dust volatilized in the electric arc has been studied; but as yet few reliable data have been collected.

The abnormal darkness of January 23rd, 1924, has been the subject of extensive investigation. The "Load diagram" for the power station in the City Road shows that at $2.30 \mathrm{p.m}$. on that day this station had to send out between 13,000 and 14,000 kilowatts, the normal output for the same time of day at that time of year being 10,000 kilowatts. At the height of the obscuration no lights were visible beyond 500 feet; the impurity was equal to a precipitation of between 1 and 2 milligrams per cubic metre.

D. Frasmr Harris. 